\title{
Safety, Tolerability, and Effect on Opioid Use of Meloxicam IV Following Orthopedic Surgery
}

This article was published in the following Dove Press journal:

Journal of Pain Research

\author{
Kipling P Sharpe' \\ Richard Berkowitz ${ }^{2}$ \\ William A Tyndall ${ }^{3}$ \\ David Boyer ${ }^{4}$ \\ Stewart W McCallum (iD $)^{5}$ \\ Randall J Mack ${ }^{5}$ \\ Wei $\mathrm{Du}^{6}$ \\ 'OrthoArizona, Gilbert, AZ, USA; \\ ${ }^{2}$ Phoenix Clinical Research, Tamarac, FL, \\ USA; ${ }^{3}$ University Orthopedics Center, \\ Altoona, PA, USA; ${ }^{4}$ Shoals Clinical \\ Research Associates, LLC, Florence, SC, \\ USA; ${ }^{5}$ Baudax Bio, Inc., Malvern, PA, \\ USA; ${ }^{6}$ Clinical Statistics Consulting, Blue \\ Bell, PA, USA
}

Objective: A Phase 3 randomized multicenter, double-blind, placebo-controlled trial (NCT02720692) compared once-daily intravenous (IV) meloxicam $30 \mathrm{mg}$ to placebo, when added to the standard of care pain management regimens, in adults with moderate-tosevere pain following major elective surgery and concluded that meloxicam IV had a safety profile similar to placebo and reduced opioid consumption.

Methods: In this post hoc subgroup analysis of orthopedic surgery subjects, 379 subjects received meloxicam IV $30 \mathrm{mg}$ or IV-administered placebo every $24 \mathrm{hrs}$ for $\leq 7$ doses. Safety was assessed via AEs, laboratory tests, vital signs, and ECG, with an emphasis on specific AEs, including injection site reactions, bleeding, cardiovascular, hepatic, renal, thrombotic, and wound healing events. Daily opioid consumption was assessed during treatment.

Results: Among meloxicam IV-treated subjects, $64.7 \%$ experienced $\geq 1$ AE versus $68.8 \%$ of placebo-treated subjects. Investigators assessed most AEs to be mild or moderate in intensity and unrelated to treatment. Total opioid consumption (36.8 $\mathrm{mg}$ versus $50.3 \mathrm{mg}$ IV morphine equivalent dose; $P=0.0081$ ) and opioid consumption during time points $0-24,24-48,0-48$, and 0-72 hrs were statistically significantly lower in the meloxicam IV group.

Conclusion: Meloxicam IV demonstrated no significant differences in the number and frequency of AEs versus placebo in subjects following orthopedic surgery. Opioid consumption was reduced in the meloxicam IV group versus placebo.

Trial registration: ClinicalTrials.gov (Identifier: NCT02720692).

Keywords: meloxicam IV, NSAID, orthopedic surgery, postoperative pain, safety

\section{Introduction}

Managing pain following orthopedic surgery can be challenging as post-orthopedic surgery patients report high pain scores, likely related to the nature of bone injuries. ${ }^{1,2}$ Effective pain management is important because uncontrolled postoperative pain is associated with several adverse outcomes, including delayed recovery, longer hospital stays, and increased morbidity. ${ }^{3,4}$ Guidelines for the management of postoperative pain strongly recommend an integrative approach, including the use of multimodal analgesia. ${ }^{5,6}$ This approach advocates the use of a variety of medications, routes of administration, and techniques that result in a synergistic and more effective approach to pain relief. ${ }^{5,7}$ Multimodal analgesia regimens are also a central component for enhanced recovery after surgery protocols and procedurespecific pain management initiatives. ${ }^{8,9}$ A major goal of multimodal pain management is the reduction in the need for opioids, which are associated with several well-documented risks (eg, dependence, abuse, diversion, hyperalgesia) and
Correspondence: Randall J Mack

Baudax Bio, Inc., 490 Lapp Road, Malvern PA 19355, USA

Tel + I 4843952470

Fax + I $484395247 \mid$

Email rmack@baudaxbio.com 
adverse events (AEs), including respiratory depression, nausea, vomiting, and constipation. ${ }^{10-12}$

Nonsteroidal anti-inflammatory drugs (NSAIDs) are commonly recommended for incorporation in multimodal postoperative pain management regimens following orthopedic surgery. ${ }^{13-15}$ These agents have analgesic, antiinflammatory, and opioid-reducing effects; however, they can be associated with AEs (eg, bleeding, cardiovascular complications, and renal effects) that have the potential to limit their use. ${ }^{13,16}$ Thus, a detailed examination of the safety profile of investigational NSAIDs or new formulations of known NSAIDs is important.

Meloxicam is a long-acting NSAID with preferential cyclooxygenase (COX)-2 inhibition that has antiinflammatory, analgesic, and antipyretic properties. ${ }^{17}$ The drug has been available in an oral formulation for many years; however, a limitation of oral meloxicam is poor aqueous solubility that results in slow absorption and a slow onset of action. This is evidenced by an observed peak plasma concentration that occurs 9 to 11 hrs after an orally administered dose of $30 \mathrm{mg} .{ }^{17}$ Consequently, oral meloxicam is not suitable for the treatment of acute pain. A novel nanocrystal formulation of meloxicam that can be given by intravenous (IV) bolus injection is being developed for moderate to severe pain management alone or in combination with other analgesics.

The safety and efficacy of meloxicam IV was investigated in three Phase 2 clinical trials using validated models for both hard- and soft-tissue surgeries, including bunionectomy, hysterectomy, and dental impaction. ${ }^{18-20}$ In these studies, once-daily administration of meloxicam IV provided onset of analgesia as early as 15 mins postdose, with maintenance of analgesic effect over a 24-hr period in subjects with moderate-to-severe postoperative pain. The drug was generally well tolerated, with an incidence of AEs that was comparable to placebo.

In phase 3 trials using validated models of subjects with postoperative pain following soft-tissue surgery (abdominoplasty) ${ }^{21}$ and hard-tissue surgery (bunionectomy), ${ }^{22}$ subjects who received meloxicam IV had a statistically significant reduction in pain intensity versus subjects randomized to placebo. In both studies, meloxicam IV demonstrated a safety profile comparable to placebo with respect to number, severity, and frequency of AEs.

A recent phase 3 multi-center, randomized, doubleblind, placebo-controlled study evaluated the safety and tolerability of meloxicam IV $30 \mathrm{mg}$ in adults scheduled to undergo major elective surgery with an inpatient hospital stay $>24$ hrs (clinicaltrials.gov identifier: NCT02720692). ${ }^{23}$ The primary objective, evaluation of meloxicam IV safety and tolerability, was assessed by incidence of AEs and serious AEs, physical examination, vital signs, clinical tests, electrocardiograms (ECGs), wound evaluation, and postoperative opioid consumption. The clinical study enrolled a heterogeneous subject population in order to study the use of meloxicam IV under a wide range of procedures, including both hard- and soft-tissue surgeries. Here, the safety and tolerability findings from a subpopulation of subjects in this study who underwent orthopedic surgeries are reported.

\section{Methods}

\section{Study Design}

This was a post hoc subgroup analysis of a phase 3 multicenter, randomized, double-blind, placebo-controlled trial evaluating the safety of meloxicam IV in adult subjects undergoing major surgery, including, but not limited to, orthopedic procedures (eg, total hip or knee replacement), open or laparoscopic abdominal surgeries, or gynecological surgeries and a range of other soft-tissue surgeries (clinicaltrials.gov identifier: NCT02720692). ${ }^{23}$ The study was conducted at sites in the United States, Canada, Australia, and New Zealand (Supplemental Table 1) between March 2016 and April 2017; all subjects provided written informed consent. The protocol was reviewed and approved by the central Institutional Review Board (IRB) with additional review by local IRBs where required and was performed according to the International Conference on Harmonisation Good Clinical Practice Guideline for Industry and, where applicable, the principles of the Declaration of Helsinki. Study randomization was stratified into two groups: subjects who underwent an orthopedic procedure and those who underwent a non-orthopedic procedure. This post hoc analysis evaluated the safety and opioid-reducing effects of meloxicam IV among the subgroup of subjects in the strata undergoing a range of orthopedic procedures (Table 1).

\section{Dosing}

Subjects who met postoperative randomization eligibility criteria were randomized (3:1 using a computer-generated block randomization scheme) to IV treatment with meloxicam $30 \mathrm{mg}$ or placebo, administered as a bolus injection every 24 hrs. Randomization was stratified by subjects 
Table I Summary of Orthopedic Surgery Types

\begin{tabular}{|c|c|c|c|}
\hline $\begin{array}{l}\text { Orthopedic } \\
\text { Surgery, n (\%) }\end{array}$ & $\begin{array}{l}\text { Meloxicam IV } \\
30 \mathrm{mg} \\
(\mathrm{n}=283)\end{array}$ & $\begin{array}{l}\text { Placebo } \\
(n=96)\end{array}$ & $\begin{array}{l}\text { Overall } \\
(\mathrm{N}=379 *)\end{array}$ \\
\hline Total knee replacement & II 17 (4I.3) & $39(40.6)$ & $156(21.6)$ \\
\hline Complex foot & $52(18.4)$ & $19(19.8)$ & $71(9.8)$ \\
\hline Total hip replacement & $50(17.7)$ & $18(18.8)$ & $68(9.4)$ \\
\hline Bunionectomy & $40(14.1)$ & $13(13.5)$ & $53(7.4)$ \\
\hline Spinal surgery & $10(3.5)$ & $3(3.1)$ & $13(1.8)$ \\
\hline $\begin{array}{l}\text { Total shoulder } \\
\text { replacement }\end{array}$ & $7(2.5)$ & I (I.0) & $8(1.1)$ \\
\hline $\begin{array}{l}\text { Complex shoulder } \\
\text { surgery }\end{array}$ & $6(2.1)$ & $2(2.1)$ & $8(I . I)$ \\
\hline $\begin{array}{l}\text { Total ankle } \\
\text { replacement }\end{array}$ & $\mathrm{I}(0.4)$ & 0 & $\mathrm{I}(0 . \mathrm{I})$ \\
\hline Orthopedic trauma & 0 & I (I.0) & $\mathrm{I}(0.1)$ \\
\hline
\end{tabular}

Note: *Safety set (received $\geq 1$ dose of study drug). Abbreviation: IV, intravenous.

greater than 65 years with mild renal impairment (glomerular filtration rate $60-89 \mathrm{~mL} / \mathrm{min} / 1.73 \mathrm{~m}^{2}$ ) versus other. Subjects received the first dose of study medication within $6 \mathrm{hrs}$ of the end of surgery, with additional doses administered as clinically appropriate up to a maximum of seven doses.

Concomitant NSAIDs were prohibited within 7 days prior to surgery. During surgery, subjects received the standard of care anesthesia and analgesic regimens (excluding the use of NSAID medication) according to the clinical practice of the surgeon based on the surgery type. Subjects with inadequately controlled pain could receive standard of care rescue medication. Although opioid analgesics were the most common type of rescue medication, any rescue analgesic (except for other NSAIDs) was acceptable according to the standard practice of the study site.

\section{Key Eligibility Criteria}

Male and non-pregnant, non-lactating females 18-80 years of age (inclusive) with a body mass index (BMI) $\leq 40 \mathrm{~kg} / \mathrm{m}^{2}$, scheduled to undergo major elective surgery, and in the opinion of the surgeon performing the procedure would require post-surgical IV analgesia, to remain in an inpatient setting for 24-48 hrs, and to receive at least two study doses were eligible for enrollment. Subjects were also required to meet postoperative randomization criteria that included: (1) the ability to achieve hemostasis and surgical incision closure prior to operating room discharge; (2) the surgical procedure was not longer than $12 \mathrm{hrs}$ and did not require use of $>2$ units of packed red blood cells or platelets; (3) the subject was expected to have sufficient pain to require IV analgesia; and (4) there was no evidence of respiratory insufficiency, clinically significant hypotension, bradycardia, coagulopathy, or any other abnormality, during or following surgery that, in the investigator's opinion, could significantly increase the risks of study participation.

Subjects were excluded if they had an allergy to meloxicam or other NSAIDs or excipients, were undergoing a surgical procedure in which NSAIDs were contraindicated, or had planned/actual admission to the intensive care unit. Elevated aminotransferases; history of HIV, hepatitis B, hepatitis $\mathrm{C}$; significant renal, hepatic, cardiovascular, metabolic, neurologic, psychiatric conditions; myocardial infarction or coronary artery bypass graft surgery within 12 months; active or recent bleeding (within 6 months), gastrointestinal ulceration, or known bleeding disorder; and history of alcohol abuse and positive results during drug screen were also exclusion criteria.

\section{Assessments}

Safety evaluations included assessment of AEs, clinical laboratory tests, vital signs, ECG findings, wound assessments, and opioid consumption. All AEs were classified according to the Medical Dictionary for Regulatory Activities (Version 18.1). AEs and serious AEs were assessed by investigator for intensity and causality. Particular attention was paid to AEs of special interest related to concerns associated with NSAIDs (bleeding, cardiovascular, hepatic, injection site, renal, thrombotic, and wound healing events). Surgical wound healing was evaluated by the investigator prior to discharge and at follow-up visit to determine whether healing was following a normal course and was evaluated on an 11-point scale (0-10). Opioid consumption was assessed as the IV morphine equivalent dose (IVMED) in milligrams at various time intervals: Day 1 (0-24 hrs), Day 2 (24-48 hrs), Day 3 (48-72 hrs), Days 1-2 (0-48 hrs), and Days 1-3 (0-72 hrs). Time to first opioid for pain management was also assessed in an ad-hoc analysis.

\section{Statistical Analysis}

This paper presents descriptive results from a post hoc subgroup analysis of a phase 3 safety study. The safety study sample size was chosen not based on any statistical assumption, but to meet regulatory requirement for total exposure. Sample size for subjects in the orthopedic strata was not pre-specified. The safety analysis population included all subjects treated with study drug. Safety endpoints were summarized descriptively. Differences between 
groups for opioid consumption were analyzed using an ANCOVA model that included treatment and analysis site. A non-parametric approach using rank-based analysis (as assessed by Cochran-Mantel-Haenszel row mean difference test) controlling for analysis site was also performed as a sensitivity analysis. For time to first opioid use, time to event analyses included Kaplan-Meier Log-rank test for survival curves and the Cox proportional hazards model for the determination of hazard ratio (controlling for site).

\section{Results \\ Subjects}

A total of 379 subjects underwent orthopedic surgery; demographic and surgical characteristics are summarized in Table 2. The overall characteristics of subjects undergoing orthopedic surgery were generally similar between meloxicam IV- and placebo-treated subjects. The most common orthopedic surgeries were total knee replacement, complex foot surgery, total hip replacement, and bunionectomy (Table 1). A summary of the extent of study drug exposure is summarized in Table 3 . The majority of subjects undergoing orthopedic surgery $(>85 \%)$ received either two or three doses of study medication.

Table 2 Summary of Subject Demographics

\begin{tabular}{|c|c|c|}
\hline Characteristics & $\begin{array}{l}\text { Meloxicam IV } \\
30 \mathrm{mg} \\
(\mathrm{n}=283)\end{array}$ & $\begin{array}{l}\text { Placebo } \\
(n=96)\end{array}$ \\
\hline $\begin{array}{l}\text { Age (years) }- \text { mean } \pm S D \\
\text { Age } \geq 65 \text { years, } n(\%)\end{array}$ & $\begin{array}{l}59.7 \pm 10.90 \\
109(38.5)\end{array}$ & $\begin{array}{l}59.5 \pm 12.06 \\
37(38.5)\end{array}$ \\
\hline $\begin{array}{l}\text { Sex, n (\%) } \\
\text { Male } \\
\text { Female }\end{array}$ & $\begin{array}{l}105(37.1) \\
178(62.9)\end{array}$ & $\begin{array}{l}30(31.3) \\
66(68.8)\end{array}$ \\
\hline $\begin{array}{l}\text { Race, } \mathrm{n}(\%) \\
\text { White } \\
\text { Black or African American } \\
\text { Asian } \\
\text { Multiple }\end{array}$ & $\begin{array}{l}249(88.0) \\
30(10.6) \\
3(1.1) \\
I(0.4)\end{array}$ & $\begin{array}{l}86(89.6) \\
6(6.3) \\
3(3.1) \\
1(1.0)\end{array}$ \\
\hline $\begin{array}{l}\text { Ethnicity, n (\%) } \\
\text { Hispanic or Latino } \\
\text { Neither Hispanic nor Latino }\end{array}$ & $\begin{array}{l}30(10.6) \\
253(89.4)\end{array}$ & $\begin{array}{l}12(12.5) \\
84(87.5)\end{array}$ \\
\hline $\begin{array}{l}\text { Baseline BMI }\left(\mathrm{kg} / \mathrm{m}^{2}\right)-\text { mean } \pm S D \\
\text { Surgery duration }(\mathrm{hr})-\text { mean } \pm S D \\
\text { High risk, } \mathrm{n}(\%) \\
\text { Time (hr) from end of surgery to } \\
\text { first dose }- \text { mean } \pm \mathrm{SD}\end{array}$ & $\begin{array}{l}30.2 \pm 4.7 \\
1.3 \pm 0.77 \\
79(27.9) \\
2.1 \pm 1.47\end{array}$ & $\begin{array}{l}29.8 \pm 4.8 \\
1.4 \pm 0.95 \\
26(27.1) \\
2.2 \pm 1.46\end{array}$ \\
\hline
\end{tabular}

Abbreviations: BMI, body mass index; hr, hour; IV, intravenous; SD, standard deviation.
Table 3 Summary of Study Doses Administered by Surgery Type

\begin{tabular}{|l|l|l|}
\hline \multirow{2}{*}{$\begin{array}{l}\text { Number of Doses } \\
\text { Received }\end{array}$} & \multicolumn{2}{|l|}{ Orthopedic Surgery (N=379) } \\
\cline { 2 - 3 } & $\begin{array}{l}\text { Meloxicam IV } \\
(\mathbf{n = 2 8 3 )}\end{array}$ & $\begin{array}{l}\text { Placebo } \\
(\mathbf{n}=96)\end{array}$ \\
\hline I Dose & $7(2.5)$ & $3(3.1)$ \\
2 Doses & $150(53.0)$ & $52(54.2)$ \\
3 Doses & $97(34.3)$ & $34(35.4)$ \\
4 Doses & $23(8.1)$ & $6(6.3)$ \\
5 Doses & $2(0.7)$ & $1(1.0)$ \\
6 Doses & $1(0.4)$ & 0 \\
7 Doses & $3(1.1)$ & 0 \\
\hline
\end{tabular}

Abbreviation: IV, intravenous.

\section{Adverse Events}

The overall incidence of AEs was similar between meloxicam IV-treated and placebo-treated subjects (Table 4). AEs were mild or moderate in both treatment groups. Serious AEs occurred in $2.5 \%$ of meloxicam IV-treated subjects and $4.2 \%$ of placebo-treated subjects. All serious AEs were reported as single-incident events in individual subjects with the exception of post-procedural pulmonary embolism in two $(0.7 \%)$ meloxicam IV-treated subjects. Both events of post-procedural pulmonary embolism were assessed by the investigator as unrelated to study treatment. Discontinuations due to an AE occurred in a single subject from the meloxicam IV group. There were no deaths reported during or following treatment in the study.

The most common AEs were gastrointestinal events (ie, nausea, constipation, vomiting), headache, and increased gamma-glutamyltransferase (Table 4). Although there were no statistical comparisons made, subjects in the meloxicam IV group had numerically lower incidence of common opioid-related AEs compared with the placebo group, including nausea, constipation, vomiting, and pruritus. ${ }^{12,24}$

\section{Adverse Events of Special Interest}

The incidence of AEs of special interest is summarized in Table 5. Across treatment groups, the number and frequency of bleeding, hepatic, renal, cardiovascular, wound healing, and injection site events were generally similar. Renal events in meloxicam IV subjects included acute kidney injury $(n=2[0.7 \%])$ and blood urea nitrogen (BUN) increased $(n=2[0.7 \%])$. One report of acute kidney injury occurred 14 days after administration of meloxicam IV in a subject with an elevated creatinine value and $2+$ urine protein before dosing. The other report occurred 1 day after the first dose of meloxicam IV and resolved the next day in a subject whose creatinine values were 
Table 4 Summary of Adverse Events in Subjects Undergoing Orthopedic Surgery

\begin{tabular}{|c|c|c|c|c|}
\hline \multirow[t]{2}{*}{ Event } & \multicolumn{2}{|c|}{ Meloxicam IV $(n=283)$} & \multicolumn{2}{|c|}{ Placebo $(n=96)$} \\
\hline & Events & $\begin{array}{l}\text { No. } \\
\text { Subjects (\%) }\end{array}$ & Events & $\begin{array}{l}\text { No. } \\
\text { Subjects (\%) }\end{array}$ \\
\hline$\geq 1$ Event & 410 & $183(64.7)$ & 160 & $66(68.8)$ \\
\hline \multicolumn{5}{|l|}{ Intensity } \\
\hline Mild & 248 & $137(48.4)$ & 86 & $44(45.8)$ \\
\hline Moderate & 147 & $93(32.9)$ & 72 & $43(44.8)$ \\
\hline Severe & 15 & $12(4.2)$ & 2 & $2(2.1)$ \\
\hline \multicolumn{5}{|l|}{ Relationship } \\
\hline Not related & 301 & $155(54.8)$ & 100 & $49(51.0)$ \\
\hline Possibly related & 101 & $62(21.9)$ & 57 & $32(33.3)$ \\
\hline Probably related & 8 & $4(1.4)$ & 2 & $2(2.1)$ \\
\hline Definitely related & 0 & 0 & 1 & I (I.0) \\
\hline $\begin{array}{l}\text { AE-related } \\
\text { treatment } \\
\text { discontinuation }\end{array}$ & 1 & I (0.4) & 0 & 0 \\
\hline \multicolumn{5}{|l|}{ Most Common } \\
\hline \multicolumn{5}{|l|}{ Events ( $\geq 3 \%)$} \\
\hline Nausea & 70 & $67(23.7)$ & 34 & $30(31.3)$ \\
\hline Constipation & 35 & $35(12.4)$ & 13 & $13(13.5)$ \\
\hline Vomiting & 23 & $20(7.1)$ & 10 & $10(10.4)$ \\
\hline GGT increased & 17 & $17(6.0)$ & 5 & $5(5.2)$ \\
\hline Headache & 16 & $15(5.3)$ & 5 & $5(5.2)$ \\
\hline Anemia & 13 & $12(4.2)$ & 4 & $4(4.2)$ \\
\hline Insomnia & 8 & $8(2.8)$ & 5 & $5(5.2)$ \\
\hline Dizziness & 6 & $6(2.1)$ & 7 & $6(6.3)$ \\
\hline Hypotension & 8 & $8(2.8)$ & 4 & $4(4.2)$ \\
\hline Pruritus & 8 & $8(2.8)$ & 4 & $4(4.2)$ \\
\hline
\end{tabular}

Abbreviations: AE, adverse event; GGT, gamma-glutamyltransferase; IV, intravenous.

within the reference range before and after dosing. Investigators assessed renal events as mild or moderate in intensity. One event of increased BUN was considered

Table 5 Adverse Events of Special Interest in Subjects Undergoing Orthopedic Surgery

\begin{tabular}{|l|l|l|}
\hline \multirow{2}{*}{ Event } & $\begin{array}{l}\text { Meloxicam IV } \\
(\mathbf{n = 2 8 3 )}\end{array}$ & Placebo (n=96) \\
\cline { 2 - 3 } & No. Subjects (\%) & No. Subjects (\%) \\
\hline Bleeding & $13(4.6)$ & $4(4.2)$ \\
Cardiovascular & $3(1.1)$ & $2(2.1)$ \\
Hepatic & $27(9.5)$ & $7(7.3)$ \\
Injection site & 0 & 0 \\
reactions & $4(1.4)$ & 0 \\
Renal & $3(1.1)$ & 0 \\
Thrombotic & $12(4.2)$ & $3(3.1)$ \\
Wound healing & & \\
\hline
\end{tabular}

Abbreviation: IV, intravenous. possibly related to study treatment; all other renal events were assessed as not related to study medication. Thrombotic events in meloxicam IV subjects included post-procedural pulmonary embolism $(\mathrm{n}=2[0.7 \%])$ and deep vein thrombosis $(\mathrm{n}=1[0.4 \%])$. All three subjects underwent knee surgery and had concomitant medical conditions (coronary artery disease, hypertension, dyslipidemia with a previous myocardial infarction) that predisposed them for thromboembolic phenomena.

\section{Laboratory Values, Vital Signs, Wound Healing}

Laboratory assessments related to bleeding risk and to renal and hepatic function were of interest because these are known to be class effects of NSAIDs. All laboratory measures that were out of normal range and assessed by the site investigator to be clinically relevant were recorded as AEs. Shift plots were used to evaluate changes in clinical laboratory values. Shifts from normal were similar between meloxicam IV- and placebo-treated subjects for hematocrit (60.8\% versus $59.5 \%)$, hemoglobin ( $56.8 \%$ versus $50.0 \%)$, and platelets ( $28.5 \%$ versus $31.1 \%)$. The incidence of clinically significant vital sign parameters that were reported as AEs was low and was generally similar between the meloxicam IV and placebo groups, respectively (hypotension $2.8 \%$ versus $4.2 \%$; pyrexia $3.5 \%$ versus $3.1 \%$; postoperative fever $1.8 \%$ versus $3.1 \%$; hypertension $1.1 \%$ versus $1.0 \%$; tachycardia $0.7 \%$ versus $0 \%$; hypoxia $0.4 \%$ versus $1.0 \%$; orthostatic hypotension $0.4 \%$ versus $0 \%$; procedural hypotension $0.4 \%$ versus $0 \%$; respiratory rate decreased $0 \%$ versus $1.0 \%$; and tachypnea $0.4 \%$ versus $0 \%$ ). None of the ECG shifts from normal to abnormal was considered clinically significant in either treatment group.

The mean assessment score of investigator satisfaction with wound healing 1 day following the last study dose prior to discharge was similar for meloxicam IV-treated subjects and placebo-treated subjects (Table 6). There was a low incidence of clinically significant findings on wound evaluation, with an incidence generally similar between the meloxicam IV and placebo groups (Table 6).

\section{Opioid Consumption}

The most common non-opioid rescue medications were acetaminophen, gabapentin, and pregabalin. Among orthopedic subjects, meloxicam IV was associated with significantly lower mean total opioid consumption compared with the placebo group (36.8 $\mathrm{mg}$ versus $50.3 \mathrm{mg}$ IVMED; $P=0.0081$ ). Total opioid consumption was significantly 
Table 6 Summary of Wound Assessment Parameters

\begin{tabular}{|l|l|l|}
\hline & $\begin{array}{l}\text { Meloxicam } \\
\text { IV (n=283) }\end{array}$ & $\begin{array}{l}\text { Placebo } \\
\text { (n=96) }\end{array}$ \\
\hline $\begin{array}{l}\text { Investigator Satisfaction with Surgical } \\
\text { Wound Healing* }\end{array}$ & & \\
LSD + I/Discharge & $9.6 \pm 0.69$ & $9.5 \pm 0.86$ \\
LSD + 7 days & $9.4 \pm \mathrm{I} .0 \mathrm{I}$ & $9.4 \pm 0.89$ \\
\hline Clinically Significant Wound & & \\
Assessment Parameters, $\mathrm{n}(\%)$ & & $\mathrm{I}(\mathrm{I} . \mathrm{I})$ \\
Erythema & $3(\mathrm{I} . \mathrm{I})$ & $\mathrm{I}(\mathrm{I} . \mathrm{I})$ \\
Drainage & $\mathrm{I}(0.4)$ & 0 \\
Edema & $\mathrm{I}(0.4)$ & 0 \\
Induration & $\mathrm{I}(0.4)$ & 0 \\
Hematoma & $\mathrm{I}(0.4)$ & \\
\hline
\end{tabular}

Note: *I I-point scale with $0=$ "completely unsatisfied" and $10=$ "completely satisfied." Abbreviations: IV, intravenous; LSD, last study dose.

reduced among meloxicam IV-treated subjects compared with the placebo group during most time points, including during Day 1 (0-24 hrs), Day 2 (24-48 hrs), Days 1-2 (0-48 hrs), and Days 1-3 (0-72 hrs) (Table 7, Figure 1). There was a nonsignificant decline in total opioid consumption in the meloxicam IV group during Day 3 (48-72 hrs). In an ad-hoc analysis, time to first opioid rescue medication was significantly longer in the meloxicam IV group compared with the placebo group (hazard ratio $0.615 ; 95 \%$ CI $0.479,0.789$; $P=0.0001$ ).

\section{Discussion}

Postoperative pain is an acute form of pain that is a consequence of surgical trauma and the subsequent inflammatory reaction. ${ }^{25}$ Postoperative pain is common, often undermanaged, and associated with a poorer recovery. ${ }^{25,26}$ Although opioids are a mainstay in the treatment of postoperative pain, the AEs and risks (dependency, overdose, diversion) associated with their use have prompted the investigation of alternative and complementary analgesics. ${ }^{27-29}$ NSAIDs have well-documented efficacy in the treatment of postoperative pain and have been shown to have an opioid-reducing effect and, in some cases, the ability to decrease opioid-related AEs (eg, nausea, vomiting, sedation). ${ }^{28,30}$ However, they can be associated with significant AEs such as bleeding, cardiovascular complications, and renal effects. ${ }^{13,16}$

Many orthopedic surgeries (eg, foot and ankle procedures, and total joint replacements) can be performed on an outpatient basis and only require oral analgesics after surgery for pain management. ${ }^{31}$ However, some complex orthopedic surgeries may require $\geq 24 \mathrm{hrs}$ of inpatient care
Table 7 Summary of Total Opioid Consumption (Mean \pm SD*) by Time Interval

\begin{tabular}{|c|c|c|}
\hline Interval & Meloxicam IV & Placebo \\
\hline $\begin{array}{l}0-24 \text { hrs } \\
n \\
\text { Mean } \pm S D \\
P \text { value }\end{array}$ & $\begin{array}{l}282 \\
22.1 \pm 22.75 \\
0.0032\end{array}$ & $\begin{array}{l}96 \\
31.1 \pm 30.87\end{array}$ \\
\hline $\begin{array}{l}24-48 \text { hrs } \\
n \\
\text { Mean } \pm S D \\
P \text { value }\end{array}$ & $\begin{array}{l}275 \\
11.7 \pm 18.67 \\
0.0362\end{array}$ & $\begin{array}{l}93 \\
15.7 \pm 23.92\end{array}$ \\
\hline $\begin{array}{l}\text { 48-72 hrs } \\
\text { n } \\
\text { Mean } \pm S D \\
P \text { value }\end{array}$ & $\begin{array}{l}126 \\
5.3 \pm 11.13 \\
0.2178\end{array}$ & $\begin{array}{l}41 \\
8.6 \pm 22.80\end{array}$ \\
\hline $\begin{array}{l}0-48 \text { hrs } \\
n \\
\text { Mean } \pm S D \\
P \text { value }\end{array}$ & $\begin{array}{l}282 \\
33.5 \pm 37.05 \\
0.0032\end{array}$ & $\begin{array}{l}96 \\
46.3 \pm 46.51\end{array}$ \\
\hline $\begin{array}{l}0-72 \text { hrs } \\
n \\
\text { Mean } \pm S D \\
P \text { value }\end{array}$ & $\begin{array}{l}282 \\
35.9 \pm 40.86 \\
0.0037\end{array}$ & $\begin{array}{l}96 \\
50.0 \pm 55.59\end{array}$ \\
\hline $\begin{array}{l}\text { During treatment } \\
\qquad \mathrm{n} \\
\text { Mean } \pm \mathrm{SD} \\
P \text { value }\end{array}$ & $\begin{array}{l}282 \\
36.8 \pm 42.69 \\
0.0081\end{array}$ & $\begin{array}{l}96 \\
50.3 \pm 55.74\end{array}$ \\
\hline
\end{tabular}

Note: *Intravenous morphine equivalent dose $(\mathrm{mg})$.

Abbreviations: IV, intravenous; SD, standard deviation.

and post-surgical IV analgesia. ${ }^{32,33}$ This study represents a large cohort of subjects undergoing a heterogeneous range of orthopedic procedures that required inpatient

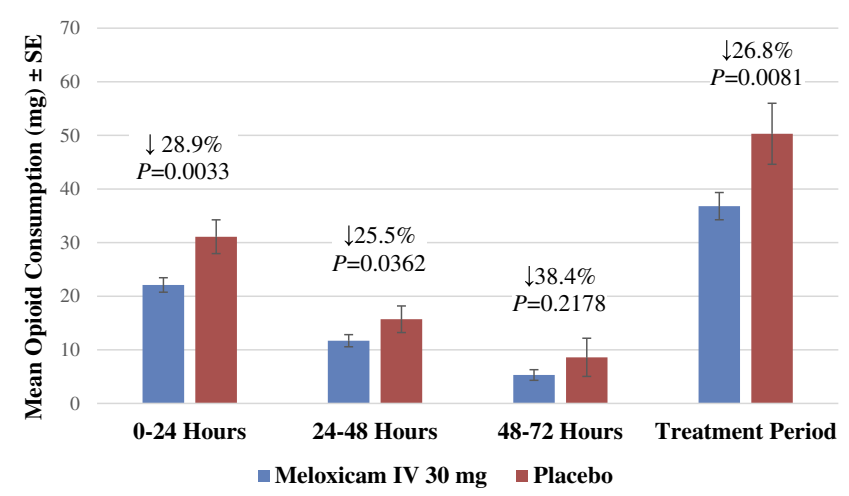

Figure I Total opioid consumption ${ }^{\mathrm{a}}$ by time interval. antravenous morphine equivalent dose $(\mathrm{mg})$.

Abbreviations: IV, intravenous; SE, standard error. 
care for $\geq 24-48 \mathrm{hrs}$, providing opportunity to evaluate meloxicam IV safety and tolerability in this population.

Results from the current subgroup analysis demonstrate that meloxicam IV $30 \mathrm{mg}$ had a similar AE profile to placebo and had an opioid-reducing effect when administered to subjects with moderate-to-severe pain following orthopedic surgery. The overall rate of AEs was similar between meloxicam IV- and placebo-treated subjects and there were no new safety signals identified. ${ }^{18,20}$ Most of the AEs were mild or moderate in intensity and considered unrelated to study treatment by the investigator. There was no evidence of an increase in AEs of special interest, such as bleeding, hepatic, renal, cardiovascular, wound healing, and injection site events, which can sometimes be of concern with NSAIDs. ${ }^{13,16}$ There were also no evident differences between treatment groups for laboratory values, vital signs, ECG, and wound healing. In particular, there were no clinically meaningful differences between meloxicam IV- and placebo-treated subjects for shifts from normal for hematocrit, hemoglobin, or platelets.

Although statistical comparisons were not performed, there was a trend toward a decrease in common opioidrelated AEs such as nausea, vomiting, constipation, and pruritus. This is consistent with other studies suggesting that NSAIDs that have an opioid-reducing effect are associated with a decrease in opioid-related AEs. ${ }^{28,34}$ For example, a meta-analysis of 22-double-blind trials including 2307 patients that evaluated NSAIDs in the treatment of postoperative pain found a positive correlation between the reduction of morphine usage and the incidence of nausea and vomiting. ${ }^{30}$ This analysis found that for each milligram of morphine spared by NSAIDs, the incidences of postoperative nausea and vomiting were decreased by $0.9 \%$ and $0.3 \%$, respectively. ${ }^{30}$ The benefit was particularly evident in the subgroup of studies conducted in orthopedic surgery, with NSAIDs associated with a $34 \%$ reduction in postoperative nausea and vomiting. ${ }^{30}$ In the current study, meloxicam IV was associated with a significant reduction in total opioid use of $>25 \%$, which corresponded to a total decrease of 12 IVMED. Thus, the reduction in opioid use in the meloxicam IV group in this study may have contributed to a lower incidence of AEs commonly associated with opioid use. Overall, these results suggest that meloxicam IV is a welltolerated option for use in pain management in patients undergoing orthopedic surgery and its use may contribute to the goal of minimizing the use of opioid medications.

A major limitation of this study is that it is a subgroup analysis of a randomized trial and was not powered to evaluate the statistical significance of differences between treatment groups for the safety variables assessed. An additional limitation is that analgesic needs can be quite different across diverse orthopedic procedures and this study did not assess pain scores as reported by subjects as a measure of analgesic efficacy. Mean opioid consumption was assessed in this study as a surrogate measure of analgesic efficacy.

\section{Conclusion}

Overall, meloxicam IV $30 \mathrm{mg}$ administered once daily was generally well tolerated and had an opioid-reducing effect in subjects with moderate to severe pain following orthopedic surgery.

Portions of this manuscript were presented at the 2017 PAINWeek National Conference; September 5-9, 2017.

\section{Abbreviations}

AE, adverse event; BMI, body mass index; BUN, blood urea nitrogen; COX, cyclooxygenase-1; ECG, electrocardiogram; GGT, gamma-glutamyl transferase; Hr, hour; IRB, institutional review board; IV, intravenous; IVMED, intravenous morphine equivalent dose; LSD, last study dose; NSAID, nonsteroidal anti-inflammatory drug; SD, standard deviation; SE, standard error.

\section{Data Sharing Statement}

Requests for study documents and patient level data will be considered on a case-by-case basis. Any requests should be sent to Randall J Mack.

\section{Acknowledgments}

Alexis Gomez, MBA (Baudax Bio formerly Recro Pharma, Inc., Malvern, PA), contributed to the data analysis and provided a factual review of the manuscript. Assistance with manuscript preparation was provided by Bret Fulton, $\mathrm{RPh}$, and Susan Martin, PhD (The Medicine Group, New Hope, PA), and funding was provided by Baudax Bio formerly Recro Pharma, Inc., Malvern, PA, USA.

\section{Author Contributions}

All authors contributed to the design and implementation of the study. KPS, RB, WAT, and DB managed the subjects and contributed to acquisition of the data and certify that their institutions approved the human protocol for this investigation and that all investigations were conducted in conformity with ethical principles of research. WD provided statistical guidance for data analysis and interpretation. All authors contributed to drafting the manuscript 
and/or critically reviewing it for important intellectual content. All have read and approved the final version for journal submission, and agree to be accountable for all aspects of the work.

\section{Funding}

Funding for this research was provided by Baudax Bio formerly Recro Pharma, Inc., Malvern, PA, USA.

\section{Disclosure}

Kipling $\mathrm{P}$ Sharpe is an employee of OrthoArizona who conducted this trial. He reports research funding for a separate study of the same drug. Richard Berkowitz is the owner/principal investigator of Phoenix Clinical Research who conducted this trial. William A Tyndall is an employee of University Orthopedics Center who conducted this trial and received clinical trials research support from Recro Pharma. David Boyer is an employee of Shoals Clinical Research Associates, LLC, who conducted this trial. Wei Du received consultancy fees from Baudax Bio formerly Recro Pharma, Inc., Malvern, PA, USA. Dr Du has been a consultant for Recro Pharma, Inc. since 2007. Randall J Mack and Stewart W McCallum are employees and security holders of Baudax Bio formerly Recro Pharma, Inc., Malvern, PA, USA. Mr Mack has multiple patents pending (application numbers 16/297,095; 16/297,020; 62/749,407; 62/755,003; all assigned to Baudax Bio, Inc). The authors report no other conflicts of interest in this work.

\section{References}

1. Gerbershagen HJ, Aduckathil S, van Wijck AJ, Peelen LM, Kalkman CJ, Meissner W. Pain intensity on the first day after surgery: a prospective cohort study comparing 179 surgical procedures. Anesthesiology. 2013;118(4):934-944. doi:10.1097/ALN.0b013e31828866b3

2. Chung F, Ritchie E, Su J. Postoperative pain in ambulatory surgery. Anesth Analg. 1997;85(4):808-816. doi:10.1213/00000539-199710000-00017

3. Cordts GA, Grant MS, Brandt LE, Mears SC. A qualitative and quantitative needs assessment of pain management for hospitalized orthopedic patients. Orthopedics. 2011;34(8):e368-e373. doi:10.3928/01477447-20110627-11

4. Pasero C, McCaffery M. Orthopaedic postoperative pain management. J Perianesth Nurs. 2007;22(3):160-172; quiz 172-163. doi:10.1016/j. jopan.2007.02.004

5. Chou R, Gordon DB, de Leon-casasola OA, et al. Management of postoperative pain: a clinical practice guideline from the American Pain Society, the American Society of Regional Anesthesia and Pain Medicine, and the American Society of Anesthesiologists' Committee on Regional Anesthesia, Executive Committee, and Administrative Council. J Pain. 2016;17(2):131-157. doi:10.1016/j.jpain.2015.12.008 6. American Society of Anesthesiologists Task Force on Acute Pain Management. Practice guidelines for acute pain management in the perioperative setting: an updated report by the American society of anesthesiologists task force on acute pain management. Anesthesiology. 2012;116 (2):248-273. doi:10.1097/ALN.0b013e31823c1030
7. Young A, Buvanendran A. Recent advances in multimodal analgesia. Anesthesiol Clin. 2012;30(1):91-100. doi:10.1016/j.anclin.2011.12.002

8. Joshi GP, Schug SA, Kehlet H. Procedure-specific pain management and outcome strategies. Best Pract Res Clin Anaesthesiol. 2014;28 (2):191-201. doi:10.1016/j.bpa.2014.03.005

9. Wick EC, Grant MC, Wu CL. Postoperative multimodal analgesia pain management with nonopioid analgesics and techniques: a review. JAMA Surg. 2017;152(7):691-697. doi:10.1001/jamasurg. 2017.0898

10. Lovich-Sapola J, Smith CE, Brandt CP. Postoperative pain control. Surg Clin North Am. 2015;95(2):301-318. doi:10.1016/j.suc.2014.10.002

11. White PF. What are the advantages of non-opioid analgesic techniques in the management of acute and chronic pain? Expert Opin Pharmacother. 2017;18(4):329-333. doi:10.1080/14656566.2017.1289176

12. Benyamin R, Trescot AM, Datta S, et al. Opioid complications and side effects. Pain Physician. 2008;11(2 Suppl):S105-S120.

13. Fischer HB, Simanski CJ, Sharp C, et al. A procedure-specific systematic review and consensus recommendations for postoperative analgesia following total knee arthroplasty. Anaesthesia. 2008;63 (10):1105-1123. doi:10.1111/j.1365-2044.2008.05565.x

14. Bourne MH. Analgesics for orthopedic postoperative pain. Am J Orthop (Belle Mead NJ). 2004;33(3):128-135.

15. Huang YM, Wang CM, Wang CT, Lin WP, Horng LC, Jiang CC. Perioperative celecoxib administration for pain management after total knee arthroplasty - a randomized, controlled study. BMC Musculoskelet Disord. 2008;9:77. doi:10.1186/1471-2474-9-77

16. McCarberg B, Gibofsky A. Need to develop new nonsteroidal anti-inflammatory drug formulations. Clin Ther. 2012;34(9):1954-1963. doi:10.1016/j.clinthera.2012.08.005

17. Del Tacca M, Colucci R, Fornai M, Blandizzi C. Efficacy and tolerability of meloxicam, a COX-2 preferential nonsteroidal anti-inflammatory drug. Clin Drug Investig. 2002;22(12):799-818. doi:10.2165/00044011-20022 2120-00001

18. Gottlieb IJ, Tunick DR, Mack RJ, et al. Evaluation of the safety and efficacy of an intravenous nanocrystal formulation of meloxicam in the management of moderate-to-severe pain after bunionectomy. J Pain Res. 2018;11:383-393. doi:10.2147/JPR.S149879

19. Rechberger T, Mack RJ, McCallum SW, Du W, Freyer A. Analgesic efficacy and safety of intravenous meloxicam in subjects with moderate-to-severe pain after open abdominal hysterectomy: a phase 2 randomized clinical trial. Anesth Analg. 2018;128(6):1309-1318. doi:10.1213/ANE.0000000000003920

20. Christensen SE, Cooper SA, Mack RJ, McCallum SW, Du W, Freyer A. A randomized double-blind controlled trial of intravenous meloxicam in the treatment of pain following dental impaction surgery. $J$ Clin Pharmacol. 2018;58(5):593-605. doi:10.1002/jcph.1058.

21. Singla N, Bindewald M, Singla S, et al. Efficacy and safety of intravenous meloxicam in subjects with moderate-to-severe pain following abdominoplasty. Plast Reconstr Surg Glob Open. 2018;6(6): e1846. doi:10.1097/GOX.0000000000001846

22. Pollak R, Gottlieb IJ, Hakakian F, et al. Efficacy and safety of intravenous meloxicam in patients with moderate-to-severe pain following bunionectomy: a randomized, double-blind, placebo-controlled trial. Clin J Pain. 2018;34(10):918-926. doi:10.1097/AJP.000000000000 0609

23. Bergese S, Melson T, Candiotti K, et al. A phase 3, randomized, placebo-controlled evaluation of the safety of intravenous meloxicam following major surgery. Clin Pharmacol Drug Dev. 2019;8(8): 1062-1072. doi:10.1002/cpdd.666

24. Labianca R, Sarzi-Puttini P, Zuccaro SM, Cherubino P, Vellucci R, Fornasari D. Adverse effects associated with non-opioid and opioid treatment in patients with chronic pain. Clin Drug Investig. 2012;32 (Suppl 1):53-63. doi:10.2165/11630080-000000000-00000

25. Prabhakar A, Mancuso KF, Owen CP, et al. Perioperative analgesia outcomes and strategies. Best Pract Res Clin Anaesthesiol. 2014;28 (2):105-115. doi:10.1016/j.bpa.2014.04.005 
26. Apfelbaum JL, Chen C, Mehta SS, Gan TJ. Postoperative pain experience: results from a national survey suggest postoperative pain continues to be undermanaged. Anesth Analg. 2003;97 (2):534-540. doi:10.1213/01.ANE.0000068822.10113.9E

27. Kaye AD, Cornett EM, Helander E, et al. An update on nonopioids: intravenous or oral analgesics for perioperative pain management. Anesthesiol Clin. 2017;35(2):e55-e71. doi:10.1016/j.anclin.2017.01.006

28. Pogatzki-Zahn E, Chandrasena C, Schug SA. Nonopioid analgesics for postoperative pain management. Curr Opin Anaesthesiol. 2014;27 (5):513-519. doi:10.1097/ACO.0000000000000113

29. Prabhakar A, Cefalu JN, Rowe JS, Kaye AD, Urman RD. Techniques to optimize multimodal analgesia in ambulatory surgery. Curr Pain Headache Rep. 2017;21(5):24. doi:10.1007/s11916-017-0622-z

30. Marret E, Kurdi O, Zufferey P, Bonnet F. Effects of nonsteroidal antiinflammatory drugs on patient-controlled analgesia morphine side effects: meta-analysis of randomized controlled trials. Anesthesiology. 2005;102 (6):1249-1260. doi:10.1097/00000542-200506000-00027
31. Beaussier M, Sciard D, Sautet A. New modalities of pain treatment after outpatient orthopaedic surgery. Orthop Traumatol Surg Res. 2016;102(1 Suppl):S121-S124. doi:10.1016/j.otsr.2015.05.011

32. Crawford DC, Li CS, Sprague S, Bhandari M. Clinical and cost implications of inpatient versus outpatient orthopedic surgeries: a systematic review of the published literature. Orthop Rev (Pavia). 2015;7(4):6177. doi:10.4081/or.2015.6177

33. Elvir-Lazo OL, White PF. The role of multimodal analgesia in pain management after ambulatory surgery. Curr Opin Anaesthesiol. 2010;23(6):697-703. doi:10.1097/ACO.0b013e32833fad0a

34. Maund E, McDaid C, Rice S, Wright K, Jenkins B, Woolacott N. Paracetamol and selective and non-selective non-steroidal anti-inflammatory drugs for the reduction in morphine-related side-effects after major surgery: a systematic review. $\mathrm{Br} J$ Anaesth. 2011;106(3):292-297. doi:10.1093/bja/aeq406

\section{Publish your work in this journal}

The Journal of Pain Research is an international, peer reviewed, open access, online journal that welcomes laboratory and clinical findings in the fields of pain research and the prevention and management of pain. Original research, reviews, symposium reports, hypothesis formation and commentaries are all considered for publication. The manuscript management system is completely online and includes a very quick and fair peer-review system, which is all easy to use. Visit http:// www.dovepress.com/testimonials.php to read real quotes from published authors. 